\title{
Medial rectus muscle cysticercosis: an assessment using ultrasonography and CT
}

\author{
Amar Pujari, Aswini Kumar Behera
}

Dr. Rajendra Prasad Centre for Ophthalmic Sciences, All India Institute of Medical Sciences, New Delhi, India

\section{Correspondence to}

Dr Amar Pujari, dramarpujari@ gmail.com

Accepted 2 November 2016

\section{DESCRIPTION}

A 9-year-old boy presented with the history of progressive pain, watering and abduction limitation for 1-week duration. Medical history revealed two episodes of recurrent congestion on the nasal side and watering 2 and 4 week's prior. On examination visual acuity was $20 / 200$ improving to $20 / 40$ with refraction and 20/20 in right and left eye, respectively; extraocular motility was severely restricted in abduction and elevation with minimal restriction in depression and adduction (figure 1). Fundus examination showed localised choroidal mount on the nasal retina without any intraocular cyst. Ultrasonography of the orbit revealed a large cyst in the medial rectus muscle with peripheral high amplitude spike echo (figure 2A). Subsequent CT imaging of the head and neck showed a well-defined large cyst in medial rectus indenting the globe with a peripheral high amplitude dot, without any intracranial foci (figure 2B). Both the ultrasonography and CT features suggested myocysticercosis with peripheral scolex.
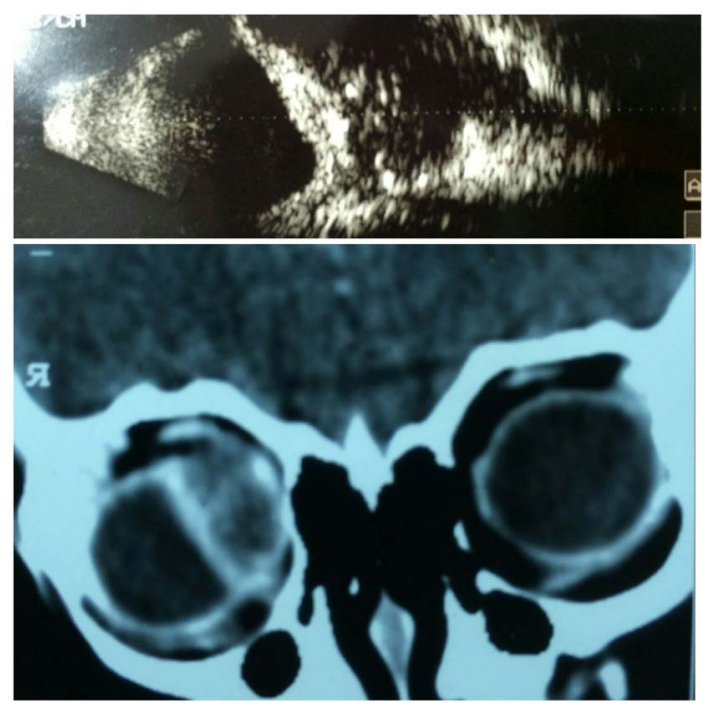

Figure 2 (A) Ultrasonography showing large cyst with scolex in the periphery along with indentation over the globe. (B) CT scan shows a large cyst within the medial rectus muscle with scolex in its periphery.
To cite: Pujari $A$, Behera AK. BMJ Case Rep Published online: [please include Day Month Year] doi:10.1136/bcr-2016217953
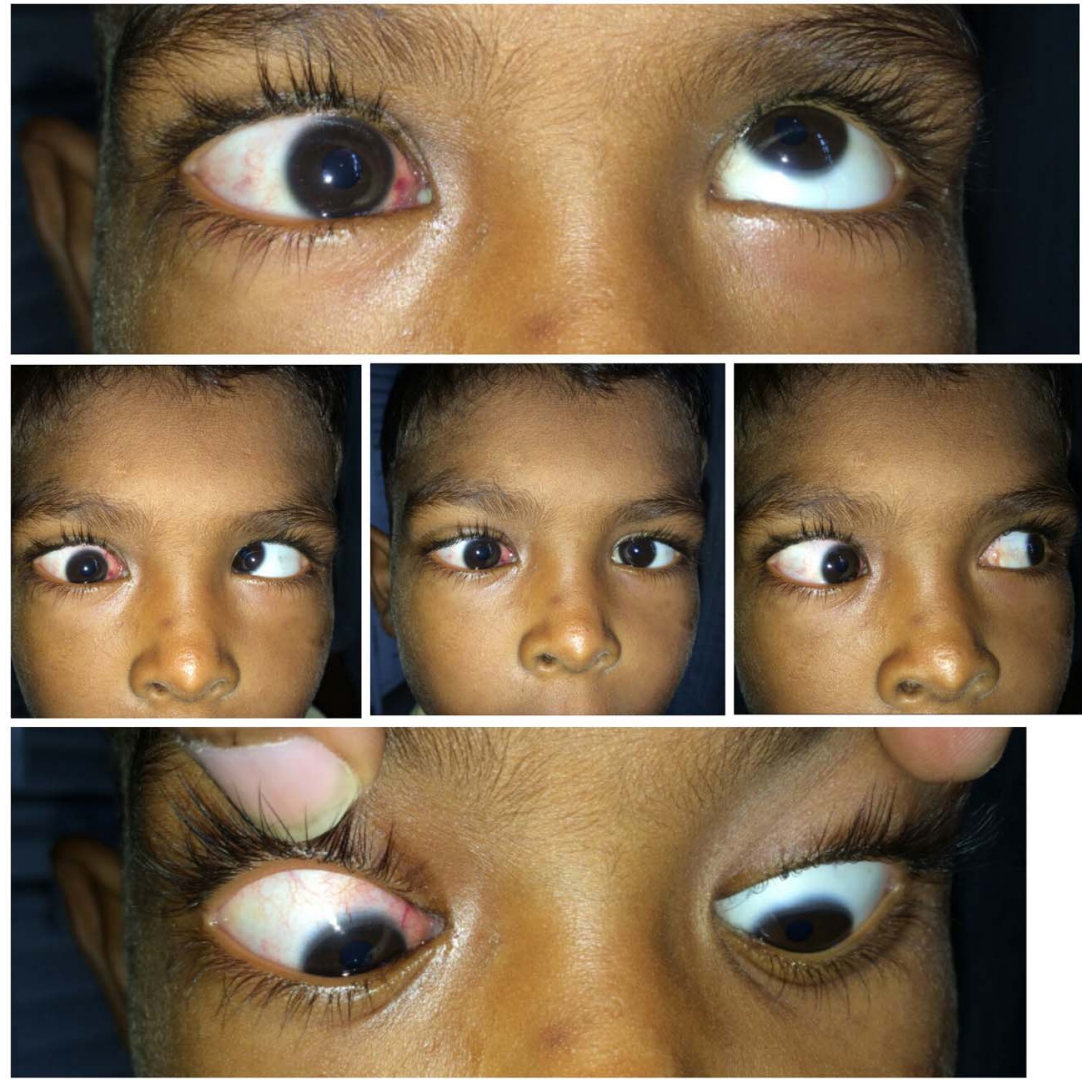

Figure 1 Severely restricted extra-ocular motility in abduction and elevation. 


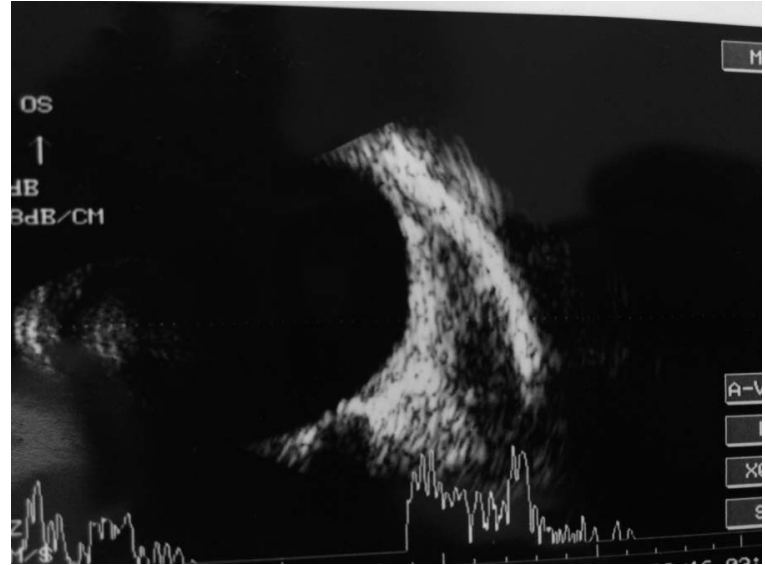

Figure 3 Ultrasonography at 6 weeks shows complete disappearance of the scolex along with reduction in the volume of cystic cavity.

The patient received tablet albendazole $(15 \mathrm{mg} / \mathrm{kg})$ along with tablet prednisolone $(1 \mathrm{mg} / \mathrm{kg})$ for 6 weeks with serially monitored ultrasonography after every 2 weeks by single observer, (Author) until the disappearance of the scolex, which disappeared at around 3 weeks and the cyst decreased in size at around 6 weeks (figure 3). At the end of 2 months, the patient is fine with regained full range of extra-ocular motility (figure 4). At the end, 3 months patient is fine without any recurrence.

The larval form of Taenia solium, cysticercus cellulosae infects humans in the endemic region due to poor sanitation, after ingestion of ova contaminated food. Extra-ocular muscles are the common site of involvement in orbital disease. The presentation can be ptosis, recurrent lid oedema, chemosis, painful proptosis, limitation of extra-ocular motility. ${ }^{1}$ The diagnosis mainly depends on strong suspicion in endemic regions and demonstration of extra-ocular muscle cyst with scolex within it on ultrasonography and CT scan. Ultrasonography is usually performed to monitor the regression of the cyst which is an easy and economic tool in developing countries. ${ }^{2}$ Treatment involves tablet albendazole $(15 \mathrm{mg} / \mathrm{kg})$ along with steroids (1$1.5 \mathrm{mg} / \mathrm{kg}$ ) in a tapering dose over a period of 4-6 weeks depending on the response. ${ }^{1-4}$

\section{Learning points}

- Extra-ocular myocysticercosis is very much prevalent in developing nations. The diagnosis is challenging in paediatric cases; it requires an insight into the prevalence and typical manifestations of the disease.

- To optimise the results ultrasonography and CT should be used meticulously.

Contributors AP investigated this patient thoroughly and diagnosed myocysticercosis, for which the patient was treated with albendazole and wysolone for 6 weeks, with complete recovery. AKB along with AP collected the data and wrote the case.

Competing interests None declared.

Patient consent Obtained.

Provenance and peer review Not commissioned; externally peer reviewed.
Figure 4 Recovery of full range of extra-ocular motility after completion of therapy.
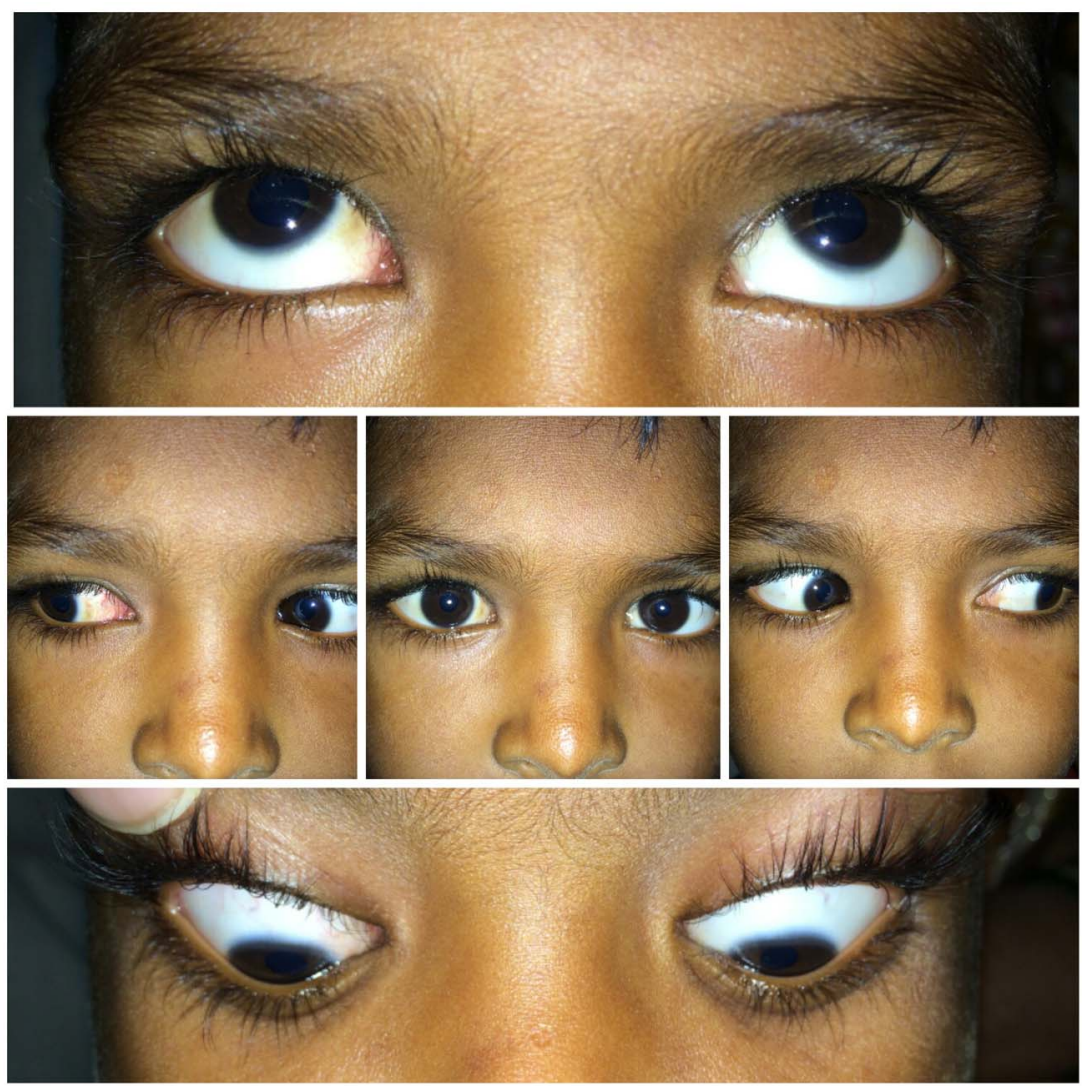


\section{REFERENCES}

1 Sekhar GC, Honavar SG. Myocysticercosis: experience with imaging and therapy. Ophthalmology 1999;106:2336-40.

2 Sundaram PM, Jayakumar N, Noronha V. Extraocular muscle cysticercosis-a clinical challenge to the ophthalmologists. Orbit Amst Neth 2004;23:255-62.
3 Puri P, Grover AK. Medical management of orbital myocysticercosis: a pilot study. Eye Lond Engl 1998;12(Pt 5):795-9.

4 Agrawal S, Agrawal J, Agrawal TP. Orbital cysticercosis-associated scleral indentation presenting with pseudo-retinal detachment. Am J Ophthalmol 2004;137:1153-5.

Copyright 2016 BMJ Publishing Group. All rights reserved. For permission to reuse any of this content visit http://group.bmj.com/group/rights-licensing/permissions.

BMJ Case Report Fellows may re-use this article for personal use and teaching without any further permission.

Become a Fellow of BMJ Case Reports today and you can:

- Submit as many cases as you like

- Enjoy fast sympathetic peer review and rapid publication of accepted articles

- Access all the published articles

- Re-use any of the published material for personal use and teaching without further permission

For information on Institutional Fellowships contact consortiasales@bmjgroup.com

Visit casereports.bmj.com for more articles like this and to become a Fellow 